\title{
Trabalho indígena na dinâmica de controle das reduções de Maynas no Marañón do século XVII
}

\author{
Fernando Torres-Londoño*
}

\section{Resumo:}

Resgatar as diversas mudanças nas formas de sobrevivência e trabalho dos indígenas decorrentes do assentamento nas missões jesuíticas de Maynas no rio Maranhão é objetivo deste artigo. Isto será feito considerando tanto o contexto das pressões espanholas por mão-de-obra, como as negociações estabelecidas entre índios e missionários.

Palavras-chaves: índios, jesuítas, Amazônia, missões e trabalho.

\section{Introdução}

Em 1638 as autoridades coloniais espanholas foram surpreendidas pela chegada a Quito de uma armada portuguesa. Saindo em 1637 de Belém e subindo pelo rio Amazonas, Pedro Teixeira conseguira chegar em Baeza, na província dos Quijos, onde já com o auxílio dos castelhanos seguiu até Quito, uma das cidades mais importantes do vice-reinado de Peru.

Saindo de Belém e subindo primeiro pelo rio Amazonas e depois pelo Napo, Pedro Teixeira tinha conseguido navegar até o porto de Napo a curta distância de Quito, alcançando uma das cidades mais importantes do vice-reinado de Peru. Sua chegada suscitou sérios temores em relação aos possíveis desdobramentos da sua empreitada, que revelava os interesses portugueses pela região. Finalmente, Teixeira foi enviado de volta à Belém, acompanhado por dois jesuítas encarregados de elaborar um informe sobre a viagem ${ }^{1}$.

$\mathrm{Na}$ época, a presença espanhola na Amazônia não era significativa. Seria no decorrer do século XVII que se consolidaria a ocupação, como resultado de um movimento que descendo dos Andes avançava em direção ao leste. Ao contrário do que se esperava no século XVI, não foram encontrados significativos recursos minerais. Resultou, porém, do avanço espanhol o contato com diversos grupos indígenas, que precisavam ser submetidos para garantir o efetivo avanço da colonização ${ }^{2}$.

Os espanhóis ou encomenderos, como nomeados na documentação, se abasteciam, na região amazônica, de mão-de-obra para suas fazendas e chácaras. Através de malocas, expressão utilizada para designar incursões para captura de indígenas de grupos considerados inimigos ou rebelados, passavam a impor o 
pagamento de tributos e obrigações de trabalho conhecidas como mitas, que, nas palavras de um missionário da época, eram piores do que a escravidão ${ }^{3}$. Em 1635, os Maynas ${ }^{4}$, um dos primeiros povos da região incorporados à esfera colonial, se rebelaram contra tais condições, resultando na condenação de alguns espanhóis à morte. As autoridades desencadearam uma cruel repressão, que a documentação apresenta sob a expressão "justiça e castigo", marcada por enforcamentos e mutilações corporais, que passaria a disseminar o terror aos soldados espanhóis.

Nesse novo contexto e atendendo a solicitações de famílias de espanhóis como os De la Vaca, que tinham pretensões de ampliar o governo de Borja, estabelecido em 1616, havia pois razões suficientes para aceitar a solicitação dos jesuítas do colégio de Quito de criar nos afluentes do Amazonas uma missão. A iniciativa foi apresentada pelos superiores jesuítas às autoridades como a melhor forma de trazer tanto para o cristianismo como para a sujeição à coroa espanhola as inúmeras populações indígenas que se mostravam arredias e com temor do que podia significar o contato com os espanhóis.

A difusão do diário do padre Cristóbal de Acuña, a respeito da viagem de retorno de Pedro Teixeira a Belém, no contexto da separação dos reinos de Portugal e Espanha, deu ainda mais força ao argumento de que a melhor garantia para a preservação dos direitos do rei de Espanha sobre a região seria o estabelecimento das missões dos padres da Companhia de Jesus ${ }^{5}$. No diário, Acuña alertava para o real perigo de uma ocupação portuguesa da região, anunciada pelas incursões de capturas de índios, e considerava que a melhor forma de barrá-la seria estabelecendo missões e fazendo dos índios cristãos e vassalos do rei da Espanha.

Em 1638, os padres Cugia e De la Cueva estabelecem às margens do rio Pastaza uma missão que seria o núcleo inicial de um vasto empreendimento missionário jesuíta na Amazônia ocidental. Até 1767, outras 152 reduções ou anexos ${ }^{6}$ seriam fundados às margens dos rios Marañón, Amazonas e afluentes, que a partir dos anos quarenta do século XVII passaram a ser conhecidos como missões de Maynas. As missões se localizavam em uma área que se estendia desde o piemonte andino até a confluência do rio Negro com o Marañón, área que atualmente faz parte dos territórios de Equador, Peru, Colômbia e Brasil. Nessa ampla área os missionários entrariam em contato com um universo indígena pluriétnico e plurilingüístico. Entre outros, habitavam na região 
os grupos Mayna, Andoa, Pinche, Urarina, Jebero, Cocama, Mayoruna e Omagua, que não formavam uma unidade política, mas mantinham relações fluidas entre si.

O projeto dos jesuítas era o de estabelecer uma rede de missões ou pueblos, que, situadas de forma estratégica e a distâncias adequadas, permitisse uma real comunicação, criando assim uma malha de relações entre os diferentes assentamentos e garantindo a unidade do empreendimento. Nesse sentido, privilegiariam a concentração das missões em alguns poucos rios da região. Para alcançar o objetivo missionário os padres entendiam que os contatos iniciais com as nações indígenas teriam que ser realizados em condições de paz, preferivelmente sem a presença de soldados, traduzindo suas boas intenções em presentes e gentilezas e através de uma comunicação direta ou mediante intérpretes. Porém, estabelecidas as reduções, não abriram mão de recorrer em certos momentos ao apoio da "justiça” de Borja, traduzida em soldados e ações disciplinares contra os indígenas insubordinados. Assim, apesar das várias críticas às ações predatórias contra os indígenas das reduções de Maynas realizadas pelos encomenderos das regiões ocupadas de forma permanente por espanhóis no pé de monte como Borja e Moyobamba, que provocaram uma significativa queda demográfica de vários povos indígenas, não concebiam os padres as missões de Maynas no século XVII como espaço separado da colonização, pelo contrário, as entendiam como novas províncias a serem integradas de forma gradual àquele espaço. Nesse sentido, as missões, subordinadas ao colégio da Companhia de Jesus de Quito e ao governo de Maynas, submetido à Audiência de Quito e ao Vice-reinado do Peru, se enquadravam no movimento de expansão da conquista espanhola ${ }^{7}$ de alargamento das áreas já conquistadas e ocupadas.

Dentre as inúmeras mudanças que resultaram da presença e atividade missionária para os povos que habitam a região, uma das mais drásticas e ao mesmo tempo base de todo o empreendimento missionário, é a que se refere ao assentamento dos povos indígenas em aldeias fixas, pueblos ou reduções. Uma variada gama de conseqüências resultou da redução dos povos indígenas, muitas delas marcando importantes mudanças nas formas de organização indígena, dentre outras o assentamento significava a introdução de novas formas de subsistência resultando na organização de novas formas de trabalho e obrigações, como também novas formas de organização do tempo e espaço. Com base nas crônicas dos missionários jesuítas do período de 1638 a 1684 e tendo como contexto o projeto missionário que estava sendo 
implantado em Maynas, o artigo recupera algumas das mudanças referentes ao trabalho indígena.

\section{Fontes}

Assim como em outros empreendimentos jesuíticos, resultaria das Missões de Maynas uma copiosa produção escrita ${ }^{8}$. A mesma ${ }^{9}$ acompanhou os jesuítas desde a fundação da ordem, que nasceu de um grupo de letrados como ordem de letrados que fazia dos estudos de filosofia, teologia e latim a sólida base para uma atuação múltipla. A escrita como diferencial da ordem adquiriu as feições que a caracterizariam através da correspondência do Padre Francisco Xavier ${ }^{10}$ sobre suas atividades missionárias na Ásia. Posteriormente, os missionários jesuítas enviados fosse ao Congo, Brasil, México, Peru, Japão ou China manteriam a prática da correspondência no empenho de tornar conhecidas na Europa as suas atuações e obras, pautada invariavelmente na premissa de que Deus, a Igreja e as monarquias católicas estavam sendo servidos no avanço do cristianismo entre os gentis. Da vasta produção de Maynas, duas obras foram selecionadas para o presente trabalho: a de Francisco de Figueroa e a de Manuel Rodríguez, respectivamente de 1661 e 1681/84.

Figueroa $^{11}$ escreve no ano de 1661 um relatório intitulado: Informe de las Misiones en el Marañón, Gran Pará o Río de las Amazonas por el padre Francisco de Figueroa, 1661. Seu texto é um informe ao provincial que visava também dar subsídios à elaboração de uma história da província jesuítica e passou a ser continuamente transcrito e copiado nas várias histórias que se escreveram posteriormente sobre as missões de Maynas, principalmente para dar conta dos primeiros 25 anos.

A obra de Rodríguez ${ }^{12}$, El Marañón y Amazonas, Historia de los descubrimientos, entradas y reducción de naciones, trabajos malogrados de algunos conquistadores y dichosos de otros, así temporales, como espirituales, en las dilatas montañas y mayores ríos de América, escrita por el padre Manuel Rodríguez, de la Compañía de Jesús, procurador general de las provincias de Indias en la corte de Madrid, com 444 páginas, é publicada em Madri em 1684. As atribuições de Rodríguez como "procurador general de las provincias de Indias" eram as de representar as missões na Espanha, cuidar das relações destas com o padroado, o Conselho de Índias, como também dentro da Companhia na chamada procuradoria de Índias. Mas principalmente o que se esperava do procurador de uma missão na Europa era que 
incentivasse o despertar de vocações para as missões e conseguisse intermediar e facilitar a ida de jesuítas para as missões do Marañón. Para tanto devia dar a conhecer e divulgar as missões de Maynas nos colégios e casas de formação das províncias espanholas, de onde deveriam sair as vocações missionárias, como também conseguir os recursos para fazer possíveis as onerosas e demoradas viagens. Seu trabalho se dava entre reitores de colégios, superiores de casas e diversos provinciais, devendo convencêlos da necessidade e urgência de colaborar com a pregação do Evangelho e a salvação das almas, nas distantes, difíceis, mas férteis missões do Marañón.

Foi com a perspectiva de divulgar as missões na Europa que, desde Quito e depois em Santa Fé, o padre Rodríguez começou a reunir informações e registros que dessem fundamento a seu trabalho de proselitismo missionário, de modo que balizasse sua história como verdadeira. Continuou o trabalho de coleta de materiais na Espanha e Roma, o que finalmente lhe deu condições de escrever um livro sobre as missões do Marañón. Rodríguez redige a crônica sob a idéia de que o Marañón tinha sido reservado por Deus como campo de ação para a Companhia de Jesus. Aparece no texto como um espaço distante, desconhecido, de montanhas impenetráveis e rios perigosos, mas com enorme multidão de gentio que precisava ser salva, sendo a Companhia de Jesus o melhor instrumento de que dispunham a Igreja e o Rei para chegar àqueles confins e neles implantar reduções.

Apesar de ambos os textos terem como assunto principal o projeto missionário, guardam diferenças em função das especificidades dos objetivos que visavam. Sendo o texto de Rodríguez de divulgação que visava ganhar vocações para a obra, dá uma clara ênfase às possibilidades ou oportunidades que as terras do Maranhão guardavam para aqueles que se dispusessem a difundir a palavra do Evangelho. Já o texto de Figueroa, sendo um informe sobre o andamento de uma obra da companhia, tem clara ênfase na discussão dos pontos que era necessário superar para efetivamente implementar o projeto missionário. Nesse sentido os conflitos e dificuldades que se opõem ao projeto missionário e a forma de solucioná-los são mais claros e evidentes no seu texto do que no do padre Rodríguez, em que, apesar de serem listadas as dificuldades da obra, a ênfase recai na potencialidade que ela tem.

\section{As missões: dispositivo de sujeição modelador de cristãos e súditos}


A ação missionária evangelizadora, tal como era entendida pelos padres missionários jesuítas do Marañón, definia o percurso a ser seguido e gerava o registro de leitura das novas experiências. Importava no marco de tal projeto, antes de mais nada, que a ação atingisse o maior número de indivíduos, pois apenas um coletivo significativo poderia justificar que o empreendimento do Marañón fosse privilegiado em relação a vários outros que se abriam como possibilidades para a Companhia ${ }^{13}$. À questão da quantidade se somava uma outra referente à qualidade, não interessava aos jesuítas a mera administração de sacramentos, mas uma conversão "verdadeira"14. Influía no entendimento de que uma conversão dessa índole exigiria um longo processo de evangelização, dentre outras razões, a visão que os missionários tinham dos indígenas, considerados selvagens e infantis, e o fato de a pedagogia inaciana ter por princípio a noção de repetição. Nesse sentido não é de estranhar que Figueroa, falando dos Jeberos, descreva um processo de cinco anos até a administração do batizado:

Esta reduccion [Limpia Concepción de Jeberos] y sus anejos estuvo unos cinco años sin que se tratasse de bautizarle toda la gente, sino á solos niños y moribundos, hasta que estuvo bien poblada y dispuesta. (Figueroa, 1986, p. 182)

Sendo os padres as figuras desencadeantes e diretoras do processo, entendiam os jesuítas que a única forma de garantir que o trabalho de uns poucos missionários tivesse uma máxima repercussão seria dar as condições para que o mesmo tivesse contato com o maior número de indivíduos possíveis. Tanto Figueroa como Rodríguez comentam em seus textos que as populações indígenas estavam dispersas e afastadas uma das outras, sendo necessárias demoradas jornadas de viagens difíceis, perigosas e nem sempre possíveis para ir de um povoado a outro. Não é de estranhar que, em função do projeto que tinham em mente e das condições que encontraram, os missionários tenham considerado condição primeira e essencial para o desenvolvimento de suas atividades o assentamento das populações indígenas em reduções ou pueblos. Apenas com os índios assentados haveria possibilidade de realizar o demorado trabalho que poderia levar os indígenas a um estado de "maturidade" que permitisse a administração dos sacramentos, já que como Figueroa observa:

(...) se les da á entender con preguntas breves, y como á niños se les da á beber en sorbos pequeños. (Figueroa, 1986, p. 162)

Apenas uma demorada convivência criaria a possibilidade da longa série de sucessivas repetições, "pequenos goles”, que culminaria nos sacramentos. Demorada já 
que o projeto não visava a experimentação do novo, mas a difícil mudança do filtro do paladar, o que tornava necessária a repetida e contínua exposição ao novo. Entendiam os missionários que só compensaria dar início a tal trabalho se os índios se dispusessem a abandonar seu modo de vida itinerante e passassem a se fixar na redução. Apenas sob esta condição os jesuítas entendiam que haveria a possibilidade de organizar um cotidiano regrado de repetições, "quartas, sextas-feiras e domingos", necessário para a catequese:

Esta es la causa, y el no aver tierras, ni modo de que se pueblen juntos, de que los maynas tengan y no estén tan industriados como otros que tienen asistente al Padre que los enseña, á que se llega y no ayuda poco el ser tan cimarrones, porque huyéndose, á poco tiempo se olvidan de todo. En la Ciudad solamente tienen mejor comodidad de aprender quando sirven en ella, donde está y vive el Padre, que miércoles, viernes y domingo les hace la doctrina y examina el rezo. (Figueroa, 1986, p. 169)

Porém não eram índios como os maynas que já estavam incorporados à esfera espanhola que os missionários pretendiam atingir, senão aqueles que estavam às margens do espaço colonial espanhol. Uma das maiores dificuldades em relação a esses grupos, que também pesava no entendimento de um longo e demorado processo evangelizador, era a referente à comunicação. Pelo fato de se tratar de um universo plurilingüístico, praticamente cada nova nação contatada colocava a dificuldade de uma nova língua. Entre as diversas línguas faladas na região estavam as do tronco MacroTupi como a Cocama, a Omagua, e a Yurimagua, e as do tronco Pano como a Chayahuita e a Mayoruna ${ }^{15}$. Nesse sentido, a questão da comunicação era outro aspecto a limitar o raio de alcance da ação missionária. Rapidamente os primeiros padres chegaram à convicção de que o seu trabalho se veria muito limitado caso tivessem que aprender a língua de cada nova nação. A figura do intérprete indígena, denominado língua ou ladino nas crônicas, se impôs como solução. Fazia parte do projeto missionário introduzir o quéchua, língua do Ingá, nos documentos, para criar um denominador comum nas missões. Porém até chegar a tal ponto, tão demorado quanto a própria catequese, os intérpretes passavam a ser figuras essenciais para o projeto. A respeito dos problemas de comunicação e escrevendo sobre os maynas que se encontravam em Borja, Figueroa escreve:

A los principios se confessaban los ladinos en la lengua del Ingá general, las Quaresmas y los bocales solamente in articulo mortis, y algunos para casarse, por no obligarles á confessarse la Quaresma por intérprete. Quando ubo aptitud, se començaron á confessar en la materna (...) (Figueroa, 1986, p. 168) 
Se no caso dos maynas assentados as dificuldades de comunicação tinham sido grave entrave para a catequese, nada fazia supor que a situação seria outra para os grupos indígenas marginais ao espaço colonial. Esses grupos, apesar de não incorporados à área colonial, começavam a sofrer as consequiências de uma proximidade cada vez maior, que se traduzia em entradas ou malocas de soldados e encomenderos para a captura de mão-de-obra indígena, como também em diversos surtos epidêmicos ${ }^{16}$. Começava a resultar de tudo isso uma grave alteração demográfica quando da chegada dos jesuítas, que fragilizava as nações indígenas para as quais a figura do espanhol já se cristalizara como claro e poderoso inimigo. Souberam os missionários tirar partido do conflito que encontraram não só se apresentando como figuras diferentes do espanhol soldado ou encomendero, mas principalmente incluindo na série de argumentos usados para demover os povos índios ao assentamento a apresentação das reduções como garantia de proteção à ação dos espanhóis:

(...) asegurándoles principalmente que teniendo doctrina no les harian daño los españoles, ni llebarian sus hijos, que es lo que sumamente sienten. (Figueroa, 1986, p. 200)

Como resultado de várias entradas, alguns grupos indígenas acabariam por se decidir pelo assentamento nas reduções missionárias. Não poucas dificuldades precisavam ser vencidas até se chegar a esse ponto, algumas delas são abordadas nas cartas do padre Cugia a respeito de suas primeiras entradas a Jeberos. Dentre outras dificuldades coloca que não encontrou cacique com quem pudesse

(...) assentar poco en órden á su población y dotrina, que parece abrá de dar no poco trabajo, por la gran division en que está toda esta nacion, repartida en varias rancherías, distantes entre sí dos, quatro y seis leguas, algunas, tres y quatro, jornadas. (Figueroa, 1986, p. 178)

Já em uma entrada posterior a Jeberos, o padre Cugia teve muito trabalho para visitar os doentes e administrar o batismo em diversos lugares. Assim Figueroa diz que na sua redução pouco se adiantava:

(...) cada qual queria se hiciesse la poblacion en su ladronera, que tienen por su patria, de que se ausentan con grandíssima repugnancia; con que aunque se les hacian varios razonamientos, no surtia la cosa. (Figueroa, 1986, p. 179)

Foi apenas na quarta entrada que o trabalho do padre começou a ter resultados, na ocasião achou:

(...)ya puesta en obra vnas cien casas, y que trataban de lebantar las restantes, aunque huvo mucho travajo en algunos que estaban muy rehacios, costó tiempo y buena diligencia y traça su conclusión, hasta que, en fin, todos acabaron de reducirse y poblarse juntos. (Figueroa, 1986, p. 179) 
À questão do assentamento ou fixação das populações indígenas podiam eventualmente somar-se outras duas variáveis: o deslocamento da população da área tradicionalmente ocupada e o agrupamento de diferentes populações em um mesmo assentamento ou pueblo. Relatando a fundação da redução de Nuestra Señora del Loreto de Paranapura, Figueroa dá conta de um assentamento que envolve essas variáveis, o que segundo seu relato teria sido prática comum. No caso estavam sendo reunidos os grupos de Paranapuras, Chayavitas e Muniches, na nova redução do rio Guallaga. Segundo o informe, o motivo para se reunir estas nações teria sido o de serem populações muito pequenas e o fato de viverem em partes pouco habitadas e remotas, que não facilitavam a comunicação. A idéia da redução em Paranapura teria partido do padre Santacruz, que atendia aos Jeberos que moravam não muito distantes dali. Assim:

(...) se determinó á embiar otro Padre que tratasse de fundar vna reduccion de paranpuras, chayavitas y muniches, procurando juntar todas estas naciones, por ser pequenas, reçagos de las malocas de Moyobamba, que cada vna sola no era bastante; juntas harian algo de importância. (Figueroa, 1986, p. 199)

Segundo o informe, o padre que tinha sido mandado junto com os principais dos Paranapuras e Chayavitas:

(...) suvió con ellos á que se viesse y registrasse el puesto más á proposito para que se poblasen ellos y los muniches. Visto el que parecia más acomodado y que caia en medio, para que en él se llamassen y juntassen estas naciones, mientras se disponian las cosas y se hacian las sementeras (...). (Figueroa, 1986, p. 200)

Figueroa registra no seu informe que os Chayavitas, "sentian dejar sus tierras", e se lamentavam ao descer até o local escolhido, com "canoas, herramientas y otras cosas que abian menester" (Figueroa, 1986, p. 200), ajudados pelo padre. Também a mudança pesava aos Muniches, o seu cacique Juanio teria argumentado muito contra a saída das suas terras:

Assí lo hizo, admitiendo el ser dotrinados, pero dando solucion (por ser de juicio y capacidad) á todas las razones que se la avia propuesto para mudarse, todo en órden á no dejar sus tierras. (Figueroa, 1986, p. 200)

Embora Figueroa revele as preocupações que os índios manifestavam quando defrontados com a mudança que a redução colocava, tendo sua atenção voltada para o projeto missionário que passava a se abrir, não se demove da convicção de o assentamento na redução ser essencial e escreve: 
Assí, á más no poder, se ha de procurar sacar los tales indios á donde puedan morar con dotrina y comunicacion, y ser corregidos y dirigidos por la justicia, sin la qual no se entablará cosa. (Figueroa, 1986, p. 202)

O assentamento começava com a construção da igreja e casa e a partir desse momento tinha início o processo de evangelização. O padre Cugia, em uma carta a propósito do contato que tinha iniciado com os Jeberos, faz uma formulação sucinta do percurso que a ação missionária deveria seguir. Escreve a propósito do novo grupo contatado que se haveria de prosseguir com sucesso "en su reduccion, enseñança y bautismo" (Figueroa, 1986, p. 178). Do relato da fundação e do cotidiano das diferentes reduções de Maynas ${ }^{17}$ se recupera efetivamente o percurso formulado por Cugia, porém não na abstração da sua formulação que delineia um trajeto aparentemente sobre o vácuo. $\mathrm{O}$ que se recupera desses vários relatos é o percurso definido, porém, como padrão de mudanças de hábitos e costumes indígenas, que se conseguiam realizar com maior ou menor grau de sucesso, revelando tensões e conflitos por parte das populações indígenas em função da nova realidade das missões.

A fundação da redução surge como marco inicial do empreendimento evangelizador tanto no relato de Figueroa como no de Rodríguez e marco de rupturas em relação ao modo de vida indígena anterior. É o projeto missionário e a figura específica do padre que conferem significado à nova organização que passa a ser plasmada nas reduções e que haveria de significar mudanças de variados níveis para as populações indígenas. Falando ainda a respeito dos Jeberos, Figueroa tece o seguinte comentário:

Entre estas gentes, por ser de tal génio que no se les asienta ni arrayga la fee de una vez que la perciban y crean, sino que la conserban con la assitencia y contínuo regadio de quien se la predica, no conviene, ni harán cosa de importancia en materia de dotrina, andando de vnas partes en otras, sin entablarse en ninguna. Y es tal la calidad deste gentío, que teniendo Padre que les asista, se pueblan, moran en sus pueblos y obran lo que les importa: en faltándoles el Padre, se desparraman como ganado sin pastor, por la natural inclinación que tiene á passeos largos y á sus ladroneras antiguas y modo de vivir, distantes vnos de otros, y á sus barbaridades, que las buelben á exercitar fácilmente en viéndose sin quien les corrija y mire. (Figueroa, 1986, p. 182)

(...) porque assí éstos como muchos ladinos y enseñados en huidas, en sus ladroneras se olvidan de lo que savian, se entorpezen y embrutezen, como exercitados en la vida de brutos y fieras. (Figueroa, 1986, p. 164)

O comentário de Figueroa ilustra a forma em que as mudanças introduzidas pela ação missionária serão decodificadas e narradas pelos padres: sempre na perspectiva do 
processo de evangelização. O que o trecho descreve é o pior dos cenários possíveis para o missionário, a reversão completa do trabalho realizado: a regressão ao estado de barbárie original. O papel que cabe ao missionário, como atento guia de um rebanho, é “corrigir e olhar" instaurando um programa de adequação a um modelo que ele detêm. Quaisquer outros significados, associados aos hábitos e costumes que se abandonavam ou adquiriam, elaborados na perspectiva indígena, dificilmente seriam acolhidos nas narrativas que mantêm o registro de leitura do cotidiano das missões invariavelmente na dependência do programa de adequação do projeto evangelizador. Da mesma forma que a figura do padre era depositária dos significados da redução e na sua ausência o processo desandava, muitos dos significados da nova realidade para os índios são perdidos pelo código de leitura daquele que faz o relato. A ausência de uma figura portadora dos significados indígenas não invalida a informação que os mesmos possam ter, porém é necessário lembrar que se trata de fragmentos dispostos sob uma perspectiva particular e específica.

A citação anterior é uma das várias passagens a expor a importância do assentamento e da presença permanente e vigilante do padre, idéias centrais da racionalidade jesuítica evangelizadora, tal como se expressou na América colonial. Porém a possibilidade de empreender tal tarefa era determinada e dada por outras condições que não meramente a racionalidade missionária jesuítica e tinha imbuídos outros aspectos que não meramente evangélicos. As especificidades que a ação missionária teve na América surgem com claridade quando comparada com a realizada na mesma época em outras regiões como o Japão e a China, que não se estruturou em torno das missões. Tinha sido naquelas terras que a obra missionária pioneira do padre Francisco Xavier sentara as bases do modelo missionário, com abordagens em muitos aspectos totalmente diferentes das que acabariam sendo elaboradas na América. A racionalidade missionária jesuítica nas terras do Marañón podia assumir a forma do assentamento em reduções em função do contexto em que se desenvolvia. O jogo específico de forças na área, região de fronteira de um processo de conquista militar, permitia fazer emergir a idéia de assentamento não apenas como forma mais racional, mas principalmente como possibilidade viável. No caso dos missionários jesuítas no sudeste asiático, que não trabalharam no contexto de uma conquista, nem chegou a se cogitar tal possibilidade. A abordagem e o trato em relação aos povos indígenas no contexto de uma conquista que já tinha submetido povos como os dos Andes, que os 
espanhóis entendiam como mais avançados, gerava pautas muito diferentes daquelas que se elaboravam em outras regiões como o Japão ou a China. Havia na América uma estrutura de forças que abria a possibilidade de a racionalidade missionária ser elaborada em termos de máxima eficiência, sem precisar contemplar os hábitos e formas de vida do gentio do Marañón. O que no Marañón podia ser desconsiderado e na Ásia precisava ser incorporado ao projeto não resultava de uma falha da compreensão ou formação dos padres aqui enviados. Muito do que nas terras do Marañón passou a ser corrigido não pertencia ao programa de evangelização, mas a um segundo programa de adequação que deveria ser realizado junto ao anterior.

A questão do assentamento na redução não é pautada apenas pela questão da evangelização. A prática de sujeição que ela instaurava passava a modelar outros aspectos que não apenas aqueles da esfera espiritual. A sujeição que passava a se manifestar em inúmeros aspectos que a nova organização missionária instaurava respondia a um segundo programa, aquele que visava modelar a figura do súdito real. $\mathrm{O}$ cristão a ser plasmado nas missões devia também ser súdito do rei. E assim como a catequese, a aprendizagem necessária para o desempenho deste novo papel também demandava um longo tempo. Se inicialmente a condição de súdito ficava sacramentada na sujeição ao padre, devia aos poucos passar a se alicerçar no tributo, sujeição da colônia ao rei.

\section{Trabalho, obrigação e negociação nas missões}

A partir dos vários relatos das fundações de missões é possível recuperar um padrão geral no que se refere às obrigações que os índios assentados passavam a ter. As descrições das novas formas de organização da vida em redução são sempre elaboradas em contraposição ao estado "selvagem e bárbaro"18 das formas de vida dos povos indígenas. Nesse contexto as mudanças introduzidas pela redução são sempre apresentadas com carga positiva em oposição ao estado anterior com forte conotação negativa.

Faziam parte das obrigações que os índios reduzidos passavam a ter não apenas participar das atividades religiosas, mas se responsabilizar pela construção da igreja e vivenda dos padres, como também pelo seu sustento. A fundação da redução começava com a construção da igreja e casa do padre, tal como tinha acontecido dentre outros quando da redução dos Jeberos (Figueroa, 1986, p. 180) e também na redução do 
Guallaga (Figueroa, 1986, p.196). A organização destes pueblos era definida pelo padre $^{19}$, de acordo aos seus próprios conceitos de espaço.

A outra obrigação que se impunha aos índios desde o momento da sua redução era a referente ao sustento do padre. Na crônica de Figueroa se recupera uma única menção a respeito de um missionário trabalhar efetivamente junto com os índios nos afazeres de sobrevivência, como caça, pesca ou agricultura. Salvo esta exceção, o padrão geral do informe descreve diferentes modos de os índios realizarem a obrigação do sustento do padre:

Por imposición del Govierno de Borja, hacen de comunidad sementeras y chacras de iucas, plátanos, maiz, barbasco, algun algodón para bestirse, casas de vivienda y otras cosas necesarias al vivir, en lugar del estipendio que deben pagar para el sustento del Padre que los dotrina. En tierras tan pobres y desbalidas, no ay otro modo para sustentarse, ni se hallará por dinero, que no corre, no lo ay en ellas. No ayuda poco para el sustento el haber dispuesto la justicia que cada semana acudan dos indios que llaman mitayos á buscar algo en los montes y quebradas, y cada dia lo traygan al Padre. Assí lo hacen, trayendo, ya el mono, ya el papagayo y otros pájaros y animales, ó el pescado, palmitos y barias cosas de montería, y frutos que se hallan en los bosques y quebradas. (Figueroa, 1986, p. 191)

Acuden cada semana dos indios à buscar el sustento del Padre, que traen cada dia, conforme lo hallan. Lo más ordinario es pescado y tortugas, por ser el principal mantenimiento desta gente y hallarlo en su rio y lagunas." (...) "Para el mesmo sustento del Padre hacen algunas sementeras de plátanos, yucas, maiz, y suelen acudir con camaricos [presentes]. También siembran algun algodón, que en parte suple el vestido del Padre, de los de su casa y de pobres. (Figueroa, 1986, p. 197)

A responsabilidade em relação ao sustento dos padres criava não apenas uma nova obrigação, como principalmente exigia a sua realização em grande parte sob novas modalidades como decorrência da fixação das populações. O relato dos missionários dá conta de que a maioria dos povos indígenas não estava fixada, e que mudavam as aldeias em decorrência das suas necessidades de subsistência. Com o assentamento, a agricultura passava a ter maior importância, sendo para muitos grupos indígenas uma nova modalidade de realizá-la. A obrigação do sustento do padre, que Figueroa faz questão de lembrar ser uma disposição do governo de Borja, traz imbuída uma primeira forma de tributação e, por conseguinte, implica a produção de um excedente. Este devia cobrir o sustento do padre, mas no caso de ir além das suas necessidades seria distribuído entre "los de su casa y de pobres". A distribuição deste excedente passava 
também a ser definida pelo missionário, marcando a "sujeição" indígena e uma das formas de autoridade do missionário.

Outra mudança introduzida pelos missionários quanto às formas de subsistência foi a introdução de gado, como já tinha sido feito em missões de outras regiões. A esse respeito Figueroa comenta:

Para ayuda de su sustento tienen catorce cabeças de ganado bacuno y alguno de cerda. (Figueroa, 1986, p. 197)

(...) quatro ó seis cabeças de ganado bacuno y algunas aves, de que cuydan los índios. (Figueroa, 1986, p. 225)

As cabeças de gado iam diminuindo

(...) muriéndose de flacas, fuera de algunas que han sido ayudadas à morirse con lançadas y beneno de las cerbatanas que algunos indios han intentado, hiriéndolas por el daño que reciben en sus sembrados, ó por sus antojos, y por la gran plaga de murciélagos que ay. (Figueroa, 1986, p. 192)

Ao contrário do que tinha acontecido em outras regiões, a criação de animais domésticos, principalmente gado, não prosperou da forma desejada, fosse pelas condições do ambiente ou como resultado da ação indígena. Figueroa faz menção à dificuldade de conciliar as sementeras com a criação de gado. Mas, além de tal dificuldade, é possível que a atitude em relação ao gado estivesse também marcada por outras questões referentes aos valores indígenas, para os quais não apenas a introdução do gado passava a significar uma mudança quanto aos hábitos alimentares, como também uma nova forma de relacionar-se com o universo animal. Se no caso do gado apenas se pode supor a existência de um conflito, em outras situações o conflito decorrente das mudanças aparece claramente colocado na perspectiva do missionário. Tal é o caso de certas formas de subsistência indígena que passavam a entrar em conflito com as novas formas de organização da redução, principalmente por implicar a saída dos índios da missão e interferir desta forma na organização almejada pelos padres. O padre De la Cueva aponta as dificuldades de conciliar formas de subsistência indígenas com a nova organização das reduções. Escreve a esse respeito:

Querer quitarles que la mita de tortugas no salgan y las gasten en los arenales de Marañon, Pastaza y Guallaga. Que la mita de los zapotes no la gasten en los montes, y assí las demas mitas y temporadas que los meten en sus anchuras, es quererse oponer á las más furiosas corrientes. (Figueroa, 1986, p. 185)

(...) y aviendo bibido tan á su voluntad y fieras costumbres, al presente están con suma sujeción, que aun para sus passeos en tiempo de tortugas y frutas, pescas y otras cosas necesarias á su sustento, piden licencia al Padre, quien les señala los 
dias que han de tardar, porque no falten mucho de sus casas. (Figueroa, 1986, p. 190)

Os comentários do padre De la Cueva, além de evidenciar, as tensões, deixam entrever principalmente um espaço de negociação entre missionários e índios que ia resultando em uma construção gradual de ações aceitas ou interditadas. Se o primeiro comentário do padre dá ênfase à dificuldade de se opor "á las más furiosas corrientes" dos hábitos indígenas e à dificuldade de introduzir novas modalidades na subsistência de forma que garanta o ganho de um excedente, daí a ênfase a contemplar um consumo além do imediato, o segundo comentário ainda sobre os mesmos hábitos indígenas de subsistência não traz uma carga tão negativa quanto à do primeiro. $\mathrm{O}$ que faz toda a diferença entre a primeira situação e a segunda é o espaço ganho pelo missionário, a saber, a "sujeição" dos índios, que, apesar de manterem os seus hábitos, passam a praticá-los somente com a "licença" do padre. Dificilmente o missionário daria tal permissão em uma outra época que não aquela propícia para a atividade em questão, porém a necessidade de ter que contar com a aprovação do padre significava a incorporação por parte dos índios dos atributos da sua autoridade.

Acompanhando os relatos do desenrolar das missões, além do padrão geral de mudanças mencionado anteriormente, é possível verificar que, a medida que a interação entre missionários e índios aumentava, outras formas de trabalho indígena eram incorporadas pelos missionários. Estas outras atividades, que nem sempre surgem associadas a uma obrigação como as anteriores, costumam estar relacionadas a questões privilegiadas pelos padres por serem de grande ajuda para o projeto missionário, o que explicaria o fato de se recuperar em relação às mesmas valorações positivas. É também em relação a estas atividades que com maior freqüência se verifica a dinâmica de negociação. Duas delas merecem destaque e envolvem o uso de trabalho indígena para o transporte e proteção dos missionários.

A menção aos canoeiros e a sua importância é recorrente tanto em Figueroa como em Rodríguez. Em um universo com forte componente aquático, entre outros motivos pelo fato de as comunicações se realizarem principalmente por vias fluviais, os cronistas são quase unânimes em reconhecer tanto a perícia dos índios como canoeiros ${ }^{20}$ como o seu conhecimento das redes fluviais. O reconhecimento e uso das capacidades indígenas no que se refere ao transporte era de fundamental importância para um projeto missionário que pretendia maximizar a ação dos poucos padres disponíveis, fazendo que 
cada um tivesse sob sua responsabilidade mais de uma redução ou pueblo. Apenas uma forma de transporte eficiente, como a propiciada pelos canoeiros, poderia permitir que os missionários dessem conta da assistência a sua rede de pueblos. Sendo grande a dependência dos missionários em relação aos índios na questão de transporte, pressupunha um elevado grau de confiança. As crônicas dão conta de que muitas das rebeliões indígenas se materializaram na quebra deste elo, abandonando os índios ao missionário e privando-o do transporte, marcavam uma sentença praticamente garantida de morte.

Uma aliança ainda maior entre missionários e índios se observa quando os primeiros passam a confiar aos segundos questões referentes à segurança. Em particular é interessante o episódio da redução dos Jeberos, em que após uma rebelião estes passam a assumir a função de segurança, como claro resultado de uma negociação. A esse respeito Figueroa escreve que após a rebelião os Jeberos tinham se transformado em:

(...) frontera que tiene la ciudad para su resguardo y de los Padres, para que otras gentes no se atreban á intentar alçamientos y barbaridades, porque ben que tienen los españoles gente fiel de quien balerse cuando lo intenten. (Figueroa, 1986, p. 188)

(...) sirbiéndoles con fidelidad en las armadas y descubrimientos que se hacen para pacificar nuebas naciones y reducirlas al Santo Evangelio, y están por particular merced reserbados de mita y tributo, dedicados solamente á las cosas de guerra y servicio de los Padres en lo tocante á descubrimientos y reducciones. (Figueroa, 1986, p. 188)

Segundo o relato de Figueroa, após terem ameaçado o padre De la Cueva teria havido uma intervenção militar para sufocar a rebelião dos Jeberos. Como resultado do triunfo espanhol, missionários e soldados teriam montado uma "encenação" de enforcamento, da qual as lideranças jeberas teriam sido salvas graças à magnânima intervenção dos missionários ${ }^{21}$. Apesar de Figueroa escrever que tal desfecho teria sido o merecido, não pontua a contradição de a continuação explicar que os Jeberos se transformaram na "fronteira" de resguardo a proteger tanto as cidades como os padres das ações de outros grupos indígenas não reduzidos. O desfecho da rebelião de Jeberos só se entende no quadro de um jogo de forças em que a saída negociada resultava a melhor opção para as partes envolvidas por não haver um claro predomínio de nenhuma delas. Aparentemente, o levantamento dos Jeberos teria colocado em xeque um investimento de mais de cinco anos, que apontava para uma missão promissora e 
decisiva para o avanço espanhol em direção ao Marañón. Tanto o levantamento, como a demonstrada capacidade para articular alianças com Cocamillas e Paranápuras e estender suas guerras ao Marañón, teriam convencido aos espanhóis, missionários e soldados, que uma sólida "amizade" com eles seria indispensável para os planos de permanência e expansão na região. Apenas a hipótese de uma aliança selada entre as partes explica a concessão de importantes privilégios como a isenção de mita e tributo, que passava a marcar a aliança entre os Jeberos e a ordem colonial.

Tanto as figuras dos canoeiros como a dos guerreiros Jeberos a serviço dos missionários permitem visualizar formas de negociação entre missionários e índios, nem sempre claramente explicitadas. Elas apontam para uma construção gradual da "sujeição" nas áreas missionárias, diferente daquela que era praticada nas áreas de efetiva ocupação espanhola, que não deve ser entendida como uma alternativa à colonização, mas como específica de uma região de fronteira em que importantes mudanças estavam acontecendo. A questão da sujeição, com os diferentes desdobramentos que poderia adquirir em situações particulares como a da rebelião de Jeberos, coloca em evidência um aspecto algumas vezes negligenciado da atividade missionária jesuíta, aquele referente à formação de fiéis súditos ao rei.

A sujeição visada pelos jesuítas fica clara nos relatos das missões bem-sucedidas aos olhos dos padres: ela se traduzia na introjeção do princípio de autoridade materializada na obediência do súdito para com o superior. Recuperando avaliações de Figueroa a respeito de diferentes grupos indígenas não reduzidos, que apresentam um padrão consistente independentemente do povo em questão, e contrapondo-as às descrições das missões bem sucedidas, fica claro que outros elementos, que não apenas o religioso, envolvia a redução. Estes outros aspectos completavam aquele percurso missionário formulado pelo padre Cugia de "redução, ensino e batismo":

No abia govierno; cada qual hacia lo que se le antojaba y tiraba por donde queria: en las maldades y delitos que se cometian, ni abia quien los castigasse, ni los caciques tenian mano para nada. Si alguno abia agrabiado de otro, él mesmo tomaba la bengança, costumbre que es comun á las demas naciones. (Figueroa, 1986, p. 196)

(...) gente enseñada á no tener yugo ni sujeción, y á no estar atareados á cosa, sino á sus antojos. (Figueroa, 1986, p. 196)

Mucha paciencia era menester y mucha tolerancia y tesson han tenido los Padres por dotrinar y domar gente tan indómita. (Figueroa, 1986, p. 196)

Ya ban obedeciendo á sus caciques y alcaldes, y acudiendo á lo que la justicia de Borja y el Padre les manda, castigándose el que no obedece ó comete otro delito. (Figueroa, 1986, p. 197) 
Tienen sus rejidores, alcaldes, alguaciles, fiscales y zepo, donde prenden á los que merecen. (Figueroa, 1986, p. 197)

Hanse vestido hombres y mugeres, como dixe de los xeberos, aunque no con tanto lucimiento. Del mesmo modo oyen missa, tienen la dotrina y pláticas, processiones y confessiones, con los demas Sacramentos. (Figueroa, 1986, p. 197)

Ao caos dos grupos indígenas em estado de natureza, sem governo, lei e justiça, entregues à vingança, se opõe a ordem das missões que instituem a autoridade, a sujeição e a justiça, a partir da definição de funções e da possibilidade de castigos corretivos. Ao universo indistinto indígena em que o delito ficava sem punição e a agressão era respondida com a vingança pessoal, se opõe a "doutrina e polícia" das reduções, a configuração de uma hierarquia constituída por "regidores, alcaldes, alguaciles, fiscales”. Reprodução da ordem colonial, imposta em consonância com a "justiça" de Borja e replicada em novas funções introduzidas pelos padres nos pueblos. Essa nova ordem da redução, réplica da ordem colonial, é a que se aprecia nas descrições das missões bem-sucedidas como aquela de Santa Maria de Guallaga.

Uma última forma de trabalho indígena usada pelos missionários merece especial destaque, pelo fato de marcar uma posição de total convergência quanto ao uso da força entre missionários e espanhóis, trata-se dos intérpretes. A importância destes em um universo de fronteira plurilingüístico não apenas era enorme, mas essencial quando dos contatos iniciais. Resulta daí que, com exceção daqueles casos de índios que conheciam a língua de outros povos, a sua formação não podia surgir da própria interação. Nesse ponto, e apesar das críticas às intervenções de captura dos soldados, os missionários consideraram ser essa a única solução possível:

(...) que gran parte del trato y manejo con los indios ha de ser por intérprete. (Figueroa, 1986, p. 253)

Para pacificar nuevas naciones se halla por de ménos inconvenientes, quando ay comodidad, que no entren españoles de repente, ni en armadas, á sus tierras; sino que mediantes las lenguas, ó otros indios sus amigos, se comuniquen y vayan poco á poco conociendo y tratando con los Padres y con los españoles, hasta que pierdan el miedo que les tienen y con que se assutan. Desta manera se ban haciendo al trato con ellos y no padecen tanto daño. Pero no se halla en todas este modo de comunicarse, porque no tienen amigos ni lenguas de su nacion que les hablen. En tal caso, á más no poder, porque no passen sin remedio, se haze lo que se puede, como es el entrar de mano armada y coger algunos que, haciéndose ladinos en nuestro poder, sirven después de tratar, hablar y apaciguar á sus parientes. A este fin, tiene ordenado el señor Governador Don Juan Mauricio Vaca que estos lenguas se entreguen y crien á cargo de los Padres, y los exime de mita y tributo, confirmándose con las Ordenanzas Reales, que 
manda se les haga buen tratamiento y se les pague su trabajo. (Figueroa, 1986, p.251)

(...) en órden á que sirvan á los vecinos y se crien y hagan aptos en la lengua del Inga, para traer á sus parientes que están de paz ó se espera que la darán (...) no es el menor trabajo por ser idiomas diferentes, para lo qual es necesario aya intérpretes de todas las naciones, y con este fin los procuran y crian los Padres en la casa de Borja. (Figueroa, 1986, p. 165)

Despacho el Theniente General D. Diego da Armas vna escuadra de seis soldados y indios amigos, con fin de que sacasen lenguas de los gayer, para que enseñados en la del Inga, se les pueda hablar, por no hallarse idioma ni modo con que se les pueda dar á entender algo. Y cualquier cosa que con semejante gente se intenta, es como si trataran con brutos, que ni entienden ni los entendemos. (Figueroa, 1986, p. 236)

(...) que lográndose, servirán para hablar [á] su nacion y apaciguarla. (Figueroa, 1986, p. 237)

O problema dos línguas ou intérpretes é extremamente interessante porque permite entender os limites de certas elaborações do projeto missionário jesuítico, importantes para contextualizar as suas repetidas críticas às ações e procedimentos dos encomenderos. O relato de Figueroa é claro quanto à situação com que os missionários se deparavam, "ni entienden ni los entendemos". Defrontados com tal situação, Figueroa invoca o projeto a levá-los até aquelas distantes terras do Marañón. Importa que os índios "no passen sin remédio", isto é, sem a palavra de Deus e para tanto "se hace lo que se puede". A formulação de Figueroa, que atribui a conduta adotada às circunstâncias específicas dadas, abre a possibilidade de se pensar que outra seria a conduta se houvesse outras possibilidades, colocando em jogo a oposição entre querer e poder. Podemos pensar que talvez outras possibilidades teriam sido elaboradas para a obtenção de línguas se tivessem entendido existir meios para tanto, porém o que não poderia deixar de acontecer era o contato e este nascia sob o signo do "remédio". Sendo a ação evangelizadora a de remediar, se inscreve no universo indígena uma situação patológica, que determina a premência e a conduta que o contato deverá seguir. É ela que justifica a violência da captura dos línguas.

Os línguas ou ladinos criam o duplo do missionário, a saber, a do mediador na perspectiva indígena. Frutos de um ato de violência, o rapto, e educados pelos padres, dificilmente se deixaria que exercessem a função desejada caso não incorporassem também o projeto evangelizador ${ }^{22}$.

\section{As missões de Maynas e espaço colonial: tensão e transição}


De uma forma geral tanto Rodríguez como Figueroa descrevem os resultados das entradas espanholas nestas novas terras do Marañón de forma negativa. Uma das idéias centrais do texto do padre Rodríguez é a de que nas terras do Marañón a conquista militar teria fracassado, tendo apenas triunfado a espiritual, idéia já esboçada no título como "trabajos malogrados de algunos conquistadores y dichosos de otros, así temporales como espirituales". Rodríguez elabora ao longo do texto uma contraposição entre a conquista militar e a espiritual, com clara ênfase no fato de ter sido esta última a que permitiu o "descobrimento" das terras de Marañón. Em meados do século XVII o ponto mais avançado da ocupação espanhola na região era a cidade de Borja. Era dali que se exercia uma permanente pressão sobre as missões. Segundo as crônicas, os encomenderos enxergavam as nações indígenas como mão-de-obra a ser incorporada pela escravidão, produto da guerra justa, ou pela imposição de mitas ou obrigações de trabalho nas chácaras e fazendas de espanhóis. Tais formas de sujeição já tinham sido aplicadas a grupos como os Maynas, que tinham se rebelado no ano de 1635. Segundo explica Figueroa:

Hacíanse algunas injusticias graves á los indios, nacidas de ignorancia ó malicia, como era servirse de ellos como esclavos, echándoles cargas y servicios que no devian por sus tassas de tributos; quitaban á los indios sus mugeres, si eran gentiles, quando pertenecian á distintos repartimientos, diciendo no avia matrimonio entre gentiles. Sacábase mucha gente de varias provincias, yendo en armada, cogiéndola y trayéndola en gruesas tropas que repartian entre los soldados y vecinos, que son las que llaman pieças, de que se ocasionaban en essas desdichadas gente lastimosas mortandades, pues dentro de pocos dias apenas quedavan vivos la décima parte. Estas y otras insolencias avia que los llevava á su perdicion. (Figueroa, 1986, p. 158).

La causa es el irse los maynas frequentemente, ó por el trabajo y malos tratamientos que les dan los españoles, ó por el hambre, y no tener en sus pueblos y ciudad la carne y pescado con la abundancia que en los arcabucos, lagunas y ladroneras suyas, ó por ser ellos criados en la vida ancha y ociosa de los montes, sin sujeción a nadie, amicíssimos de passearse, y de andar de unas partes á otras, assi por tierra como por agua en sus canoillas (...) (Figueroa, 1986, p. 163).

A coger estos cimarrones salen de Borja de ordinario casi todos los años una y más escuadras, y los buscan con excesivo trabajo por rios, quebradas, lagunas, pantanos y espinales, passando demasiadas penalidades y hambres hasta topar con ellos, en que gastan muchos meses. Assí traen á la ciudad barias tropas en que no falta que hazer en bautismos de niños y adultos que nacieron y se criaron en sus retiros. Desde el año pasado, de sesenta han traido más de trescienta cuarenta personas (...) (Figueroa, 1986, p. 164)

As entradas com o intuito de castigar rebeliões e fugas ou bem providenciar mais índios, "sacar peças e reprimir insolências e danos", teriam feito avançar a presença 
espanhola até o rio Marañón, resultando na fundação da cidade de Borja (Figueroa, 1986, p.160). Levados às encomendas dos espanhóis, os índios sofriam maus-tratos, perdiam suas fontes de alimentação, caça e peixes, e famintos terminavam fugindo, transformados em cimarrones. Os índices de mortandade seriam extremamente altos, como indicam os trechos a seguir:

(...) porque suelen traer numerosa chusma que era bastante á que fuesse en aumento esta Provincia; pero no es assí, sino que la mayor parte de la que traen se muere en llegando á estos aires y temple de Borja, aunque no aya peste, y quando se fecundan en el monte y sus quebradas, viviendo á sus anchuras, tanto se esterilizan en este territorio (...) (Figueroa, 1986, p. 164)

A pressão sobre as populações indígenas não teria diminuído nem mesmo com as missões bem estabelecidas em 1654. Figueroa relata a tensão que suscitava a presença de soldados:

(...) tenian el ánimo puesto sino en cargar y traerse la gente que hallasen, para que se repartiesen entre ellos, que es lo que llaman piezas. Con que avia graves recelos de que viéndose en la ocasión, hiciesen alguna injusticia con estrago y mortandad de la nación que encontrasen, con otras inhumanidades, que es fuerça las aya al repartir la gente, por contentar á los soldados, apartando y dividiendo hijos de vn modo que parece esclavitud, ó es peor que esclavitud, cosa sensibilíssima para estas pobres gentes, que sin duda por ella, más que por otras incomodidades, se dejan morir. (Figueroa, 1986, p. 227)

A captura de "peças" a serem repartidas entre os soldados constituía o objetivo último das armadas que chegavam até as missões ou suas áreas de influência. $O$ fato de as entradas terem tido por fim a captura de índios revela a dinâmica predatória da colonização espanhola. Resultou das entradas de soldados e encomenderos uma acentuada queda demográfica das populações indígenas, tanto devido à captura de índios como aos diversos surtos epidêmicos que se seguiram aos primeiros contatos com os espanhóis. Daí a situação encontrada pelos missionários, que Figueroa descreve da seguinte forma:

Grande es el temor á todo lo que es español ó su nombre ó sombra. (Figueroa, 1986, p. 217)

As fontes apontam para a consciência por parte dos missionários experientes e com visão de conjunto, como Figueroa, do frágil equilíbrio que sustentava o projeto das reduções. Bastava que os espanhóis se fizessem presentes para que o árduo trabalho de persuasão realizado pelos padres durante meses, enfrentando difíceis viagens por 
riachos e matas, se perdesse, dando lugar a temores e desconfianças associadas às notícias da proximidade dos soldados. Em função de tal situação, uma das formas usadas pelos missionários nos processos de aproximação consistia em estabelecer distância e marcar a diferença em relação aos espanhóis. Várias são as passagens que relatam os modos de aproximação dos missionários e as formas pelas quais ganhavam a confiança dos povos contatados, em muitas delas se destaca que a oposição entre espanhóis e índios abria uma possibilidade de aproximação entre estes últimos e os missionários. Segundo os textos, os missionários se inseriram nessa oposição posicionando-se como mediadores do conflito, demonstrando que poderiam significar um anteparo à ação dos espanhóis. Os trechos dão indícios da compreensão que os missionários tinham a respeito dos diversos motivos que levavam os grupos indígenas a responder ao seu contato:

Ni sé si fué por el grande amor con que los receví y mucho agasajo con que los traté y alenté, ó por lo que otros les dijeron de lo mucho que favorecen los Padres á los indios, ellos se me allegaron y pegaron con tanta firmeça y con tantas demostraciones de amor y confianza como pudieran hacerlo con sus padres naturales, y aún más. (Figueroa, 1986, p. 171)

Pero es, sin duda, que costó mucho tiempo y travajo el reducirlos, mucho de agasajo y dádivas, de hachas, cuchillos, agujas, puyas, ançuelos y otras cosas que estiman. (Figueroa, 1986, p. 179)

(..) los mesmos á quien avia favorecido con tantas ventajas, pues arrastrando y muriéndome andube más de cincuenta leguas de tierra á pié, sin las del rio, por ir a Moyabamba, atravesando los cerros y cordilleras de aquél tan áspero camino, a que ellos mismos tienen horror, y sacarles de entre los tornos de aquellos ciudadanos los hijos y mugeres que les abian cautibado, sin dejar una sola pieça. No esto, ni el estar hecho su defensor y tribunario (...). (Figueroa, 1986, p. 186)

Das várias razões que as citações apresentam para dar conta dos motivos que explicam os fatores a propiciar a aproximação, as expostas nas duas primeiras são relativas às partes envolvidas, missionários e índios, destacando-se a bondade dos primeiros e os ganhos materiais que os últimos perseguiam com o contato. As duas últimas citações articulam a relação entre as partes envolvidas no contato em função de um terceiro elemento, os espanhóis, fator de ameaça para os índios, em relação ao qual os missionários se projetam como mediação de proteção, seja por meio da "doutrina" da qual são portadores ou por efetivamente mediarem a liberação de "pieças" cativos. Segundo o relato do padre Figueroa, a mediação realizada pelos missionários teria sido de grande importância para o contato, sendo rapidamente entendida pelos índios, como o ilustra o caso da aproximação dos Jeberos: 
Veian los índios el travajo que por ellos padecian los padres; el amor, cariño y agasajo con que los buscaban y trataban; el cuydado con que los amparaban y defendian de la justicia y españoles; con que ellos tambien cobraron á los Padres amor, con mucha sujeción y demostraciones de querer hacer lo que les ordenassen. (Figueroa, 1986, p. 179)

A aproximação aos Jeberos ilustra a aliança que dava base às missões e que Figueroa descreve como "amor" recíproco entre padres e índios. Ela se traduzia na mediação dos primeiros em relação aos espanhóis e na sujeição dos índios aos missionários. Uma situação semelhante é descrita em relação aos Muniches, inicialmente resistentes ao trabalho missionário, teriam acabado por ceder em função dos espanhóis de Lamas, que entendiam que, pelo fato de a redução estar na sua jurisdição, tinham direito ao serviço dos indígenas:

Y aunque á los muniches han impedido los españoles de los Lamas ó Triumpho de la Cruz, porque quieren decir que tocan á su juridicion y servicio, por huir de ellos y del trabajo que suelen darles, se vinieron á vivir en Paranapura al amparo y abrigo del Padre (...). (Figueroa, 1986, p. 204)

Segundo Figueroa, os Muniches teriam selado obediência e paz à justiça de Borja por meio dos padres que os teriam pacificado. Às imagens de predação dos espanhóis, dos quais os índios fugiam, faz contraponto aquela de bondade dos padres, pelos quais os índios teriam nutrido uma afeição tal que, ao se verem confrontados com a possibilidade de serem deixados por este, chegavam a reagir da forma que segue:

Mostraron grave sentimiento los índios, porque assí como supieron que el Padre se iba començaron á lebantar alaridos desde sus ranchos, como quando lloran sus muertos (...). (Figueroa, 1986, p. 203)

A mediação realizada pelos missionários pode ter sido importante fator de aproximação, mas dificilmente seria elemento suficiente para aceitação de todo o projeto evangelizador e de seus desdobramentos. Não apenas o assentamento em reduções implicava mudanças para os índios, como principalmente novas obrigações e trabalhos. Porém, no entender dos missionários, as obrigações e trabalhos impostos pelos espanhóis não guardavam relação com aqueles impostos por eles. Na leitura dos padres, à sombra do projeto evangelizador, as obrigações impostas aos índios eram uma questão menor, que não fazia contraponto ao enorme ganho que significava a aquisição da religião verdadeira. Isso fazia a grande diferença entre as obrigações por eles impostas e aquelas impostas pelos espanhóis e não apenas o número de obrigações ou 
volume de trabalho, mas principalmente o fato de ser uma relação desvinculada do aspecto religioso. Cabe pensar até que ponto na perspectiva indígena a avaliação das novas obrigações e trabalhos poderia incorporar tal perspectiva. As repetidas rebeliões enfrentadas pelos missionários permitem supor que na perspectiva indígena o "custo" da proteção e mediação dos padres nem sempre compensava as vantagens que trazia. Para sufocá-las recorreram os missionários em repetidas ocasiões ao "freno de la justicia" de Borja.

O informe de Figueroa deixa claro que os missionários não levavam seu projeto de estabelecimento de missões nos afluentes do Marañón desvinculados das autoridades espanholas. Pelo contrário, graças aos vínculos com o governador De la Vaca, como também pela autoridade conquistada nas reduções, os missionários se sentiam capazes de conseguir de forma gradual e segura que em um futuro não muito distante as missões de Maynas estivessem em condições de fornecer à colonização contingentes populacionais de tributários e trabalhadores, dos quais esta precisava para se afirmar e crescer. Entendiam que pela natureza dos índios, pelas dificuldades de comunicação e pelo número de nações, as reduções precisavam da segurança representada pela justiça colonial, como se depreende das citações a seguir, que fazem parte das recomendações finais do informe de Figueroa. A de número 4 sugere a mudança de Borja, capital do governo de Maynas, de forma a haver uma presença espanhola na região constante e permanente:

(...) de las províncias nuebas, y para que éstas tengan más cerca el gobierno y freno de la justicia y los Padres la escolta de sus vecinos (que aunque pocos no tienen otra de españoles), importa que dicha ciudad se passe abajo, hácia las juntas de Pastaza (...) los ay en mas abundancia abajo, tambien tierras para sementeras, realengas, al modo que las tienen arriba, donde, por distantes, no pueden los vecinos lograr el vtil de las provincias nuebas, ni otras comodidades (...) Pero es menester instar en la materia porque no desistan, como suelen en otras cosas de importancia. (Figueroa, 1986, p. 308)

Aqui as missões são chamadas de províncias novas que precisam do governo, justiça e da proteção das autoridades e povoadores espanhóis. Fica claro pela recomendação que os espaços das reduções são entendidos como "províncias novas", em processo de adequação para ser incorporadas ao domínio espanhol, das que se pode aproveitar seus recursos naturais. 
A questão da mão-de-obra indígena é abordada na terceira recomendação, que sugere a regulação da distribuição dos índios em encomiendas, propondo que não se dispersem os índios, antes que sejam mantidos concentrados:

Porque no se destruyan las reducciones y despueblen, teniendo poca gente muchos encomenderos, importa prevenir este daño (que seria bastante para dejarlas) con el señor Governador, y aun con más fuerza de Tribunal mayor, para que no se hagan encomiendas sino de número grueso, sin obligación de servicio personal, sino el de mitas pagadas, y mucho ménos de dar muchachos y chinas, si no son algunos que voluntariamente quieran darlos ó serbir ellos el tiempo que pareciere. (Figueroa, 1986, p. 308)

O texto aborda claramente a questão do usufruto da mão-de-obra indígena, estabelecendo como única ressalva a distribuição em grandes encomiendas. A outra restrição quanto ao trabalho indígena, contemplada na legislação, proibição do chamado serviço pessoal dos índios, sugere que seja substituída pelo regime de mitas pagas. Os motivos que o padre Figueroa usa para fazer tais recomendações não decorrem de qualquer avaliação em relação ao trabalho e obrigações impostas aos índios, mas obedecem estritamente àquilo que norteia os jesuítas: o processo evangelizador. A dispersão dos índios em pequenas encomiendas reproduziria o mesmo problema colocado pela dispersão dos povos indígenas, que distribuídos em grandes áreas dificultavam a ação missionária. Assim, por exemplo, ao tratar da situação dos Maynas, que quando da chegada dos jesuítas em 1638 já estavam submetidos aos espanhóis e repartidos em encomiendas, Figueroa explica que:

No ay disposicion ni modo com que se dotrine como conviene esta província de Maynas por quanto están repartidos en puestos divididos y distantes (...). (Figueroa 1986, p. 168)

Importava promover as condições que propiciassem a ação missionária e nesse sentido às críticas aos espanhóis devem ser entendidas a partir das dificuldades que as encomiendas colocavam a seu projeto e não como uma crítica à exploração da mão-deobra indígena. Segundo o relato de Figueroa, os obstáculos criados seriam os que seguem:

(...) y aunque es general en todas aquestas naciones, es mucho más en la de los maynas, por ser tan amigos de huirse y huir de los españoles, con quienes están como biolentados y aburridos, y cuyos bautismos es fuerça hazerlos en breve tiempo, porque no tienen lugar ni comodidad de gastar mucho en disponerse y deprender las oraciones, como la ay en las otras reducciones que no tienen sobre sí el embaraço de las ocupaciones en que los ponen los españoles, ni la incomodidad de Borja y sus tambos y estancias (...) (Figueroa, 1986, p. 165) 
Fica claro que a racionalidade jesuítica missionária tinha por foco a evangelização e que avaliava todo e qualquer assunto, como a questão do trabalho indígena e a exploração espanhola, em função do mesmo. Mas cabe lembrar que em algum momento o trabalho de catequese estaria concluído e que a partir de então as restrições listadas não mais seriam pertinentes.

\section{Conclusão}

As crônicas dos missionários jesuítas do século XVII no Marañón permitem entender as reduções como dispositivo de sujeição, modelador de cristãos e súditos. A racionalidade jesuítica expressada nas formas que os missionários jesuítas elaboraram como eficientes para a realização do seu trabalho evangelizador, pelas profundas mudanças que introduziam nas formas tradicionais de vida das populações indígenas, propiciavam a integração destas no universo colonial, permitindo em última instância pensar as reduções como estruturas transitórias de integração ao esquema colonial $^{23}$. Porém, o mesmo relato dá subsídios para entender que houve uma considerável margem de negociação para a implantação de tal projeto, no qual os missionários cumpriram um importante papel de mediação entre os interesses espanhóis e indígenas. Nos vários episódios em que é possível ler acordos negociados, a isenção de tributos e obrigações de trabalho aparece como sendo o benefício outorgado aos povos indígenas em troca de outros serviços de interesse para os missionários em função do seu projeto evangelizador. As dispensas sempre são caracterizadas como específicas dentro do contexto particular da situação de fronteira na qual se dava o trabalho missionário, não há relato de terem sido entendidas como definitivas ou duradouras e, nesse sentido, se constituírem em uma alternativa à ordem colonial.

A efetiva incorporação dos contingentes de mão-de-obra das missões à esfera colonial foge ao escopo deste trabalho, porém não custa lembrar que ela apenas poderia efetivamente se realizar conforme planejado pelos missionários se os índios passassem efetivamente não apenas a ser, mas também a serem vistos, como cristãos e súditos. Tal possibilidade não deve ser entendida como decorrente do sucesso do trabalho missionário, mas principalmente dos interesses espanhóis, para os quais a imagem de barbárie e selvageria índia abria a possibilidade de formas de exploração da mão-deobra indígena que ficavam interditadas no caso de se tratar de cristãos. 
TORRES-LONDOÑO, Fernando. Indigenuous work in the controlling dynamics of 17th century Maynas domination in Maranhão. História, São Paulo, v. 25, n. 1, p. 15-43, 2006.

Abstract: The aim of this article is to recover the several changes of indigenous people survival and work ways resulting from the base on the jesuitic Maynas missions at Maranhão river. This will be done by considering the context of the Spanish pressure for labor, as well as the negotiations between indigenous people and missionaries.

Keywords: indigenous, jesuits, Amazonia, missions and work.

Artigo recebido em 10/2006. Aprovado em 11/2006.

\section{NOTAS:}

* Doutor em História pela USP e Professor dos programas de Pós-graduação em História e Ciências da Religião da PUC/SP.

${ }^{1}$ A pesquisa a gerar este trabalho foi realizada no marco do grupo Índios e Missionários, na PUC/SP, integrado por Rosemeire Souza, Juliana Pedro, Jane Rodrigueiro e Roberta dos Santos. O grupo tem contado com bolsas e auxílios do CNPq, Capes e da Fapesp, a quem somos gratos.

As versões da viagem de Teixeira podem ser recuperadas em CRUZ, O. F. M. L. de la. Nuevo descubrimiento del rio Marañon llamado de las Amazonas hecho por los misioneros de la província de San Francisco de Quito, el año de 1651. Quito: Biblioteca Amazonas, 1942, p. 23. BERREDO, B. Annaes históricos do Estado do Maranhão. Iquitos: CETA/Abya-Yala, 1989, p. 298. Para uma análise dos desdobramentos da viagem de Teixeira e seu retorno a Belém, ver PEDRO, J. Embates pela memória: narrativa de descoberta nos escritos coloniais da Amazônia Ibérica. São Paulo, 2006, p. 83. Dissertação de Mestrado apresentada ante o programa de História da PUC/SP.

${ }^{2}$ PORRAS, Maria Elena La gobernación y el obispado de Mainas. Quito, Tehis: Abya-Yala, 1987, p. 32.

${ }^{3}$ A tensão desse processo pode ser verificada na relação do padre de Borja, Diego Nuñez Castaño, de 1623, que se encontra no Arquivo de Índias, publicada em BURGOS, G. Primeras Doctrinas en la Real Audiencia de Quito, 1570-1640. Quito: Abya-Yala, 1989, pp. 409-410.

${ }^{4}$ Para não confundir com diversas grafias, adotamos Cocamas e não Kokamas, Jeberos, Mayorunas e Maynas. Também adotamos a grafia maiúscula para os nomes dos povos indígenas apenas naqueles casos em que é empregado em referência à nação.

${ }^{5}$ ACUÑA, C. de. Nuevo descubrimiento del gran río de las Amazonas. In: CETA. Informes de Jesuitas en el Amazonas (1660-1684). Iquitos: Monumenta Amazónica, 1986. O diário foi dado a conhecer em Quito, em 1641, foi também traduzido ao francês em 1682 e ao inglês em 1698.

${ }^{6}$ NEGRO, Sandra. Maynas, una misión entre la ilusión y el desencanto. In: NEGRO, Sandra \& MARZAL, Manuel. Un reino en la frontera. Las misiones jesuíticas en la América colonial. Lima/Quito. PUCP, E. Abya-Yala, 1999, p. 282.

${ }^{7}$ Em 1573 o rei Felipe II promulga as Ordenanzas sobre Descubrimientos, que proíbem novas expedições e conquistas como forma de conter os gastos que delas decorriam e passa a confiar o descobrimento e a pacificação nas áreas de fronteira principalmente a missionários de ordens religiosas com apoio de pequenas escoltas ou guarnições militares. BOXER, Charles Ralph. A Igreja e a expansão ibérica (14401770). Lisboa, edições 70, 1981, p. 92.

${ }^{8}$ A esse respeito ver a antologia de textos de jesuítas do Canadá à Argentina, compilados por MARZAL, M. La utopía posible. Índios y jesuítas en la América colonial. Lima: PUC, 1992.

${ }^{9}$ Sobre o controle da escrita na Companhia de Jesus ver CASTELNAU-L’ESTOILE, C. Operários de uma vinha estéril. Bauru: Edusc, 2006, p. 72. Ainda para a correspondência ver TORRES-LONDOÑO, F. Escrevendo cartas. Jesuítas, escrita e missão no século XVI, Revista Brasileira de História, n. 43, 2002. 
${ }^{10}$ No oriente desde 1542, Francisco Xavier manteve uma importante correspondência. Em 1545 saíram à luz em Paris suas três primeiras cartas, às que se seguiram muitas outras, que passaram a ser conhecidas como cartas da Índia. Em 1596, foi publicada a primeira coletânea de 62 cartas, às que seguiram outras, ver Cartas y Escritos de San Francisco Javier. Madrid: BAC, 1953, p. 31.

${ }^{11}$ Existem na atualidade duas cópias do informe. Aqui utilizamos a nosso ver a mais criteriosa das edições existentes por ter examinado essas duas cópias, assim todas as citações são tomadas de FIGUEROA, F. Informe de las Misiones en el Marañón, Gran Pará o Rio de las Amazonas por el padre Francisco de Figueroa, 1661. In: CETA. Informes de Jesuítas en el Amazonas (1660-1684). Iquitos: Monumenta Amazónica, 1986. O padre Figueroa foi um dos primeiros missionários de Maynas e depois superior da missão. Morreu assassinado pelos Cocamas em 1666.

12 RODRÍGUEZ, M. El descubrimiento del Marañón. Madrid: Alianza Editorial, 1990. Há divergências sobre o nascimento de Manuel Rodríguez. Não se sabe se foi em Valência, Espanha, ou nas Américas. Mas se sabe pelo seu próprio texto que estudou no colégio de Quito, que também ensinou ali e que ocupou vários cargos na Companhia, até chegar a ser procurador das missões de Maynas em Madrid a partir de 1678, cargo que o fez visitar várias cidades européias, entre elas, Roma. A respeito, ver a Introdução de Àngeles Duran, p. 29.

${ }^{13}$ Em 1638, quando da fundação do primeiro núcleo em Maynas, os jesuítas já tinham missões com os índios no Brasil, Maranhão, México, Paraguay, Llanos e Orinoco, Chile e Canadá, seguindo um modelo idealizado no Peru em 1588 pelo padre José de Acosta, em seu De procuranda indorum salute, ver MARZAL, M. La utopía posible, op. cit., pp. 17 e 36.

14 Tendo por base as cartas dos primeiros missionários de Maynas, Figueroa dá um informe muito negativo no que se refere à situação de fé dos Maynas e ao trabalho de catequese com eles realizado. Aparentemente os Maynas pouco sabiam ou nada lembravam do que lhes tinha sido ensinado. A lastimável situação teria sido resultado de uma cristianização precária, realizada em parte por soldados que muitas vezes teriam batizado índios às pressas, não apenas sem o devido trabalho de catequese, como também sem ter deixado registros. Figueroa, 1986, p. 161.

${ }^{15}$ Para a questão das línguas consultamos POTTIER B. (org.). América Latina en sus_lenguas indígenas, Caracas: Monte Avila/Unesco, 1983; URBAN, Greg. História da cultura brasileira segundo as línguas nativas. In: ACUNHA, Manuela Carneiro. História dos Índios no Brasil, São Paulo, Companhia das Letras, 1992.

${ }^{16}$ As epidemias foram recorrentes, dizimando consideravelmente a população indígena. Os informes relatam a ocorrência de surtos nos anos de 1660, 1669, 1680 e 1691 no século XVII e nos anos de 1749, 1756 e 1762 no século XVIII. BORJA, Francisco. Los Maynas después de la expulsión de los jesuitas. In: NEGRO, S.; MARZAL, M. Un reino en la frontera. Las misiones jesuíticas en la América colonial, Lima/Quito. PUCP, E. Abya-Yala, 1999, p. 436.

${ }^{17}$ Rodríguez dá conta no seu texto da existência de 13 pueblos até o ano de 1666: Limpia Concepción de Xeberos, San Pablo de los Pambadeques, San Ioseph de los Ataguates, Santo Tomé de los Cutinanas, Santa María de Guallaga, Nuestra Señora de Loreto de Paranapura, Santa María de Ucayale, San Ignacio de los Barbudos, San Xavier de los Aguanos, Angeles de Roamaynas, San Antonio, San Salvador de los Zapas y Iesus de los Coronados (Rodríguez, 1990, p. 271). Em uma outra relação para o ano de 1684 relaciona dezenove pueblos: San Luis Gonzaga de Maynas, San Ignácio de Maynas, Santa Teresa de Iesús de Maynas, Los Ángeles de Roamaynas, Iesús de los Coronados, San Francisco Xabier de los Gayes, Concepción de Xeberos, Nuestra Señora de Loreto de Paranpuras, anexos de Chayavitas y Muniches, Santa María de Ucayales, Santiago de Xitipos y Chepeos, San Lorenço de Tibilos, San Xabier de Chamicuros, San Antonio Abad de Aguanos, Santa María de Guallaga, San Joseph de Maparinas, San Ignacio de Mayuranas y San Estanislao de Otanavis (Rodríguez, 1990, p. 522). A ausência de vários dos pueblos da primeira relação na segunda dá a pauta de que muitos dos assentamentos não perduraram por muito tempo, porém em alguns casos algumas reduções foram abandonadas para realizar novos agrupamentos.

${ }^{18}$ Dentre várias outras descrições que Figueroa faz eis algumas. "Sobre todo, no es poco el tormento de lidiar con troncos animados y con hombres irracionales. Tales son, comunmente hablando, los indios que se crian en estos bosques, que parecen salbajes, hombres silvestres, brutos con figura humana y hombres con acciones de brutos" (Figueroa, 1986, p. 275). Não por acaso é recorrente nas crônicas elaborações em torno da indolência indígena, que pode ser facilmente entendida como resistência às novas demandas de trabalho de produção. "He dicho que destos géneros tienen en abundancia. Pero como depende el tenerla de diligencia y de suerte y bentura en hallarla, y ésta suele faltar y mancar, no siempre abundan en sustento, antes tienen muchas veces carestía de todo, en especial los araganes que no ponen diligencia en buscarla por los rios y montes donde se halla, y mucho más algunas naciones, de quienes dicen que ni aun para sembrar las raices de yucas y semillas, que otras la ponen, contentándose para vibir con solas las 
frutas y cocos de los árboles y palmas; á esta desdicha les trae su floxera y ociosidad (Figueroa, 1986, p. 266).

${ }^{19}$ “Con esta ocasion de la paz que dieron los de la Gran Cocama, y buelta de los cocamillas á su rio de Guallaga, se vino vn cacique de los más principales de la Cocama, con la gente que le reconocía, de su voluntad á poblarse y vivir con los cocamillas, con que vnos y otros se formó una razonable población, que estuvo algun tiempo sin sacerdote que los dotrinasse hasta que abiendo benido á estas missiones el padre Bartholomé Perez las començó á dar de propósito dotrina por el mes de Setiembre del año 49, poniendo la reduccion, que estaba poblada sin órden, en forma de pueblo, señalando plaça, sitio para la iglesia, casa del Padre, y las demas con division de calles, á la orilla del rio, y dándole el título de Santa María de Guallaga". (Figueroa, 1986, p.195). Os grifos são nossos.

${ }^{20}$ Rodríguez relata em forma de epopéia a viagem do padre Raimundo, que “(...) sabiendo por la relación que escrivió el padre Acuña que los portugueses que navegaron el Marañón o Amazonas el año de mil seiscientos y treinta y ocho, subiendo por un río caudaloso que entraba en él, salieron asta la cuidad de Quito a pocos días de montañas que caminaron y que los mesmos portugueses y los padres que baxaron con ellos entraron por Archidona, teniendo por allí camino para el puerto de Napo por donde baxaron al Pará, aunque ya eran antiguas las noticias y distavan las vocas de estos ríos muchas leguas de las missiones, se aprestó para navegar a buscarlos: previno canoas y bastimentos y de sus hijos y amigos los cocamas, barbudos, aguanos y xeberos alistó soldados para su entrada por ríos y tierras no conocidas, pero que se sabía tenían naciones guerreras y caribes (...)". A busca por um caminho que facilitasse a comunicação com as missões haveria de ser bem sucedida, finalmente "(...) lo consiguieron a los cuarenta y três dias de navegación rio arriba". Chegando ao destino desejado, o padre Raimundo avalia o sucesso da empresa da seguinte forma: “(...) comunico su regozijo a los índios, como a amigos, manifestándoles lo que favorecía Dios estas empresas y como, por su providencia, sin perderse entre tantos rios no conocidos, los abía sacado al deseado puerto" (Rodríguez, 1990, pp. 307 e 311). Mesmo que a providência divina fosse uma ajuda de não pouca importância, não há como não supor que a habilidade dos cem canoeiros envolvidos tenha sido também de grande ajuda.

${ }^{21}$ A respeito das rebeliões indígenas, TORRES-LONDOÑO, F. Contato, guerra e negociação. Redução e cristianização de Maynas e Jeberos pelos jesuítas na Amazônia no século XVII, comunicação em XI Jornadas internacionais sobre Missões Jesuíticas. PUC/RS, Porto Alegre, 2006.

${ }^{22}$ Sobre estes raptos ver CHAUMEIL, J. P. na introdução a Pablo Maroni, Noticias auténticas del famoso río Marañón. Iquitos: Ceta, 1988. Monumenta Amazônica, p. 18.

${ }^{23}$ Para este papel que as missões dos jesuítas teriam cumprido na América, ver MARZAL, M. Las misiones jesuítas una utopía posible? In: NEGRO, S. \& MARZAL, M. Un reino en la frontera. Las misiones jesuíticas en la América colonial. Lima/Quito. PUCE, E. Abya-Yala, 1999, op. cit., p. 493. 